\title{
Innovative Competencies of Mining engineers in Transition to the Sustainable Development
}

\author{
Andrey Krechetov ${ }^{1, *}$, Alexey Khoreshok ${ }^{2}$, Valery Blumenstein ${ }^{3}$ \\ ${ }^{1}$ T.F. Gorbachev Kuzbass State Technical University, Acting Rector, 650000 Kemerovo, 28 \\ Vesennya st., Russian Federation \\ ${ }^{2}$ T.F. Gorbachev Kuzbass State Technical University, Director of Mining Institute, 650000 \\ Kemerovo, 28 Vesennya st., Russian Federation \\ ${ }^{3}$ T.F. Gorbachev Kuzbass State Technical University, Machinery Technology Department, 650000 \\ Kemerovo, 28 Vesennya st., Russian Federation
}

\begin{abstract}
The transition to the sustainable development posed new challenges to the system of mining higher education. They are determined by the acceleration of scientific and technological progress and widespread introduction of innovations, convergence of technologies from various industries. On the one hand, globalization and rapid technology development are constantly increasing quality requirements for the labor resources of the mineral and raw materials complex and constant improvement of their skills. On the other hand, the transition to the sustainable development provides the necessity for rational use of raw materials and environmental protection. This requires the improvement of staff support system for mining operations and the interaction of enterprises with universities training mining engineers, aimed at the innovative competencies development of future miners.
\end{abstract}

\section{Introduction}

Today, many branches of the mineral resource complex are experiencing the need for highly skilled managers and specialists, which is not only a deterrent for the development of national economies, but also one of the main reasons for the loss of life and large-scale pollution of environment caused by industrial accidents.

Along with this, the development of mining complex, the basic one for the Russian economy, has always depended on the latest development results in mining, engineering, and power industry. Mining and processing enterprises have always been high-technology facilities, where the rapid introduction of the latest developments in the production process took place. Kuzbass is not an exception; it is a region with an ultrahigh concentration of mining operations, which exert a significant load on environment. The sustainable development of such mining region is impossible without staff support, which can be guaranteed only by the existing educational system being ready to train innovative competencies for future mining engineers.

\footnotetext{
*Corresponding author: kuzstu@kuzstu.ru
} 
The leader of engineering education in Kuzbass - T.F. Gorbachev Kuzbass State Technical University - has old traditions and unique "know-how" in the field of resource base and power industry [1]. It is responsible for creating the prerequisites for the transition of the extracting region to the sustainable development changing the quality of human capital at mining and processing enterprises.

\section{Materials and Methods}

The challenges that technical universities involved in training of mining engineers will inevitably face in the first half of the 21 st century are the following:

1. The global inter-industry and inter-disciplinary integration, which enhances the development of individual industrial complexes, scientific and technological progress and structural changes in the economy, which together can dramatically change the structure of demand for engineering staff in the near future.

2. The trend towards aging of the population in industrialized countries, which is going to lead to employable population reduction and, as a result, the decrease in number of highly skilled staff which provide the operation of mineral resource and raw materials complex facilities and conduct scientific research.

3. The development of geo-information technologies and unmanned mining of mineral resources that will transfer the profession of a mining engineer to a qualitatively new level.

4. The development of aviation, space remote sensing and navigation systems, which will result in the formation of integrated control systems for the search, exploration, extraction, transportation and processing of minerals. This will greatly enhance the role of IT in training future mining engineers.

5. The development of NBIC-convergence (nano-, bio-, information-, cogno) technologies will have a revolutionary impact on the demand structure of the extractive industry in future. There will be the replacement of fossil fuels with synthetic and biomass, wide distribution of biological underground leaching of metals. Particular attention will be paid to post-mining and restoration of ecosystems by using bioremediation of soils and sub-soils contaminated with hydrocarbons. As a result, the professional competences of a mining engineer are substantially altered, as are the tasks set for him/her by the innovative development of the mineral and raw materials complex [2].

\section{Results and Discussion}

In order to meet the requirements set by the transition to the sustainable development for the higher mining education, a modern technical university should provide innovative activity in the following key areas of mining training:

- influencing on the policy in the field of mining and technical education at the regional and national levels and drawing up the recommendations and proposals for the innovative development of mining enterprises;

- implementing the concept of ideas and innovations' laboratory in the field of natural-andscientific and engineering education, as well as promoting global dialogue between universities, finding new ways for innovative development of mining education, strengthening their importance in the business community of the mineral resource complex; - providing the scientific-and-technical cooperation with enterprise-stakeholders to create an effective system for interaction between the research and production sector ensuring the demand for research and development and affecting the independence and competitiveness of the mineral and raw materials complex; 
- creating favorable conditions for the global mobility of students, post-graduate students, teachers and scientists at inter-regional, national and international levels, expansion of inter-university cooperation in the field of academic and research programs;

- developing the continuous professional education system, including all the necessary knowledge, skills and experience of innovative activity and facilitating full integration of mining specialists into the international professional environment.

To achieve the goals of innovative development based on the strategic vision of sustainable development, the technical university must complete a number of long-term tasks:

1. The development of a unified approach to assessing the quality of training and minimum threshold knowledge of mining specialists through engaging stakeholders into assessing the level of professional skills of future mining engineers.

2. The development of joint educational programs and training plans together with employers that meet modern challenges and trends in the development of mining, and use, as the multiplier, the synergy of the best international achievements of the mineral resource universities' community.

3. Conducting joint research with innovative companies in strategic scientific areas of development of the mineral and raw materials sector and making promising proposals and recommendations in the field of mining, transport and processing of mineral raw materials.

4. Equitable access for students studying at the expense of the state, own means and programs of targeted training to the educational and research infrastructure, including available scientific centers, laboratories, installations and instruments for fundamental and applied mining education.

5. Holding joint multi-university educational and scientific sessions and practices, creating joint effective systems for advanced training of teaching staff, as well as specialists and managers of the mineral and raw materials complex.

To complete a number of interrelated tasks set before the university by the imperative of sustainable development, the target area in which innovative competences will be trained should include the following:

1. Manufacturing new equipment which provides a condition for the industrial development of non-traditional sources of hydrocarbon resources.

2. The development of systems and methods for increasing the extraction of mineral raw materials, including depleted deposits of energy carriers.

3 . The introduction of systems for complex and deep processing of mineral raw materials for increasing the extraction of both main and associated components at the sites of minerals.

4. The discovery of new genetic types of deposits, as well as the expansion of the geography of search and exploration of mineral deposits.

5. The development of resource-saving technologies for complex coal enrichment for involving off-balance reserves in processing and profitable use of waste from concentrating plants.

6. Introduction of new developments that contribute to reducing the level of environmental pollution, including minimization of areas for storage and disposal of waste in the areas of mining baffles of coal mines and open pits.

7. The introduction of equipment for pre-enrichment, working on different principles, at a quarry or in a mine.

The areas of application of innovative competences of mining engineers in the transition to the sustainable development include Intelligent Mine, Green Mining, integrated development of mineral resources and energy-saving technologies for their processing, including the associated extraction of components. 
Taking into account all mentioned above, the initial range of innovative competences of the mining engineer, from which the upgrading of his university training should begin, is the following:

- understanding the basic positions of IT embedding in mining.

- the ability to rationalize the production of high-quality end products due to a new look at the international ISO quality standards;

- the ability to treat man-made waste as a resource for restoring the economy and solving environmental problems in the regions;

- the skill in applying and improving technologies for increasing the efficiency of processing resources, which will allow creating a mechanism for regulating the distribution of mineral resources among regions;

- a systematic understanding of the rational use of raw materials in the entire technological cycle of their extraction and complex processing obtaining products with high added value; - understanding the basic positions of IT and the Internet of Things-technologies.

Training of these innovative competences requires a review of the functions of a technical university, ensuring its transformation into a regional center for innovative development. In the transition to the sustainable development, the functions of Alma Mater should include the following:

1. Increasing the relevance of higher mining education as an element of high-quality and inclusive education for all throughout life and participation in the formation of mechanisms that promote the sustainable development in the mineral and raw materials complex.

To achieve that, modern technical university will need to develop concepts and mechanisms for involving stakeholders (consumers of innovations) in planning, managing, drawing up curricula and training programs for miners' training, developing and assessing their professional skills, and also for cooperation between universities and mineral resource enterprises in the region for training in the workplace.

Along with this, the university should develop and present relevant mechanisms and tools for identifying current and future mining engineers' competencies being in demand in the mineral complex in transition to the sustainable development. The success of this lies in ensuring the relevance and quality of training programs for mining engineers in the context of changes in the labor markets and innovative development of the economy.

2. Activation of scientific research at the mineral resource technical university for setting up an information basis for the development of breakthrough innovations that ensure the reduction of environmental damage from the increasing extraction of mineral raw materials.

In turn, this requires the establishment of an effective system of interaction between scientific research and educational activity of the technical university, ensuring the correspondence of higher education training programs to the real needs and prospects for the development of enterprise-stakeholders of the mineral and raw materials sector.

Technical university, accordingly, should play the role of ideas and innovations' laboratory in the field of engineering mining education, as well as promote dialogue between company-stakeholders, and search for new ways for the conceptual development of the mining and processing industry.

3. Promotion of processes and results of mining engineers' training focused on the acquisition of innovative competencies, the exchange of knowledge and the promotion of ideas and values of engineering education in mineral and raw materials sector of the economy.

To realize this function, the technical university - the center for innovative development of the region - should strive to create favorable conditions for the global mobility of students, post-graduate students, teachers and scholars and the expansion of inter-university 
cooperation in the field of educational and scientific-research programs for mineral resource and raw materials complex.

The establishment of an inter-regional center for the engineering practical training sessions within the framework of international cooperation for scientific and staff support of the extracting region in transition to the sustainable development means inclusive access to the educational and scientific infrastructure, including functioning scientific centers, laboratories, unique facilities and instruments for fundamental and applied education.

\section{Conclusion}

All mentioned above will fully determine the vector of development of scientific and educational activities at T.F. Gorbachev Kuzbass State Technical University as it is being transformed into a center for innovative development of the region and organization of engineering practical training sessions. The goal of the next decade for Alma Mater will be to increase the prestige and attractiveness of getting mining engineer profession focused on training innovative competencies in the mineral and raw materials sector.

\section{References}

1. A. Krechetov, E3S Web Conf., 15, 00001 (2017)

2. A.A. Khoreshok, S.A. Zhironkin, M.A. Tyulenev, G.A. Barysheva, V.Y. Blumenstein, M.C. Hellmer, S.V. Potyagailov, IOP Conf. Ser.: Mater. Sci. Eng., 142: 1, 012122 (2016) 
